\title{
Influence of Factors on the Adoption and Use of ICT-Based eHealth Technology by Urban Corporate People
}

\author{
Masuda Begum Sampa1 ${ }^{*}$, Md. Nazmul Hossain ${ }^{2}$, Md. Rakibul Hoque ${ }^{2}$, Rafiqul Islam³, \\ Fumihiko Yokota4, Mariko Nishikitani4, Akira Fukuda1, Ashir Ahmed1 \\ ${ }^{1}$ Graduate School of Information Science and Electrical Engineering, Kyushu University, Fukuoka, Japan \\ ${ }^{2}$ Faculty of Business Studies, University of Dhaka, Dhaka, Bangladesh \\ ${ }^{3}$ Medical Information Center, Kyushu University, Fukuoka Japan \\ ${ }^{4}$ Institute of Decision Science for Sustainable Society, Kyushu University, Fukuoka, Japan \\ Email: *sampa@f.ait.kyushu-u.ac.jp
}

How to cite this paper: Sampa, M.B., Hossain, Md.N., Hoque, Md.R., Islam, R., Yokota, F., Nishikitani, M., Fukuda, A. and Ahmed, A. (2020) Influence of Factors on the Adoption and Use of ICT-Based eHealth Technology by Urban Corporate People. Journal of Service Science and Management, 13, 1-19.

https://doi.org/10.4236/jssm.2020.131001

Received: October 31, 2019

Accepted: January 4, 2020

Published: January 7, 2020

Copyright $\odot 2020$ by author(s) and Scientific Research Publishing Inc. This work is licensed under the Creative Commons Attribution International License (CC BY 4.0).

http://creativecommons.org/licenses/by/4.0/

\begin{abstract}
The aim of this study is to investigate the influence of the factors that affect the use of a PHC system (portable health clinic, an eHealth technology) by urban corporate people in Bangladesh. This study uses the first and second versions of the technology acceptance model and the unified theory of acceptance and use of technology model as the foundation. Additionally, health awareness factors are incorporated to develop the research model. Structural equation modeling was used to analyze a sample size of 264 urban corporate people in Bangladesh. Based on the total effects, the key to promoting the future use of a PHC system lies in the three most important factors: perceived usefulness (0.659), intention to use (0.454), and health awareness (0.447). These factors have a positive and direct influence on use. The findings offer proactively important and practical guidelines to service providers, implementers, and policymakers to promote the use of eHealth technology for regular health checkups.
\end{abstract}

\section{Keywords}

Portable Health Clinic, eHealth, Future Use, Perceived Usefulness, Health Awareness, Urban Corporate People, Structural Equation Modeling

\section{Introduction}

New methods and tools in the healthcare sector are growing gradually through the continuing innovation in medicine and technologies [1]. Along with the 
scarcity of medical infrastructure (e.g., clinic and doctors) and the speedy advancement in Information and Communication Technology (ICT), remote healthcare systems, such as eHealth, mHealth, telemedicine, and telemonitoring, are receiving paramount consideration worldwide [2]. More than half of the world's population does not receive all of the essential services that they need. One hundred million people are pushed into extreme poverty because of their health expenditures, forcing them to survive on just $\$ 1.90$ or less a day [3]. According to the World Health Organization (WHO), more than one-quarter of the world's countries including Bangladesh has a critical healthcare workforce shortage [4]. In Bangladesh, only 4.7 doctors are available for every 10,000 people [5]. eHealth technology, which is a healthcare system that uses ICT, is an important way to solve the scarcity of current medical facilities.

The demand for ICT-based eHealth systems is increasing each day. Advanced technologies (e.g., IoT, BigData, Machine Learning) are being applied to improve the system's efficiency. However, the social adoption of eHealth, especially in developing countries, has not been completely understood. Increasing the acceptability of eHealth technology in developing countries such as Bangladesh is necessary.

Because of the potential benefits and various eHealth initiatives in place, many studies have been conducted to determine the acceptance of eHealth technology. However, most were conducted in developed countries, such as European countries, the United States, Canada, and Australia [6] [7] [8]. Although the deployment of eHealth technology is essential for developing countries in which access to quality healthcare is hindered by poor governmental policies, political crises, and lack of a healthcare infrastructure (e.g., clinics, doctors) [9], very few studies were conducted in these countries, such as Bangladesh.

Researchers found performance expectancy, effort expectancy, facilitating condition and reinforcement factor having a significant impact on behavioral intention to use telemedicine by clinician in Nigeria [10]. On the other hand, perceived usefulness, and computer self-efficacy was shown to have a positive and significant impact on Telemedicine acceptance by public hospitals in Malaysia [11]. A study among 600 families in one particular rural area in Bangladesh found that consumers' age, occupation, and purchasing power have a significant influence on their acceptance of eHealth services from a PHC (portable health clinic) system [12]. Another study in the same rural area in Bangladesh identified social reference, advertisement, attitude toward the system, and perceived system effectiveness as influencing the acceptance of a PHC system [2]. However, because both of these studies focused on only rural areas, and the data analysis did not use structural equation modeling, estimating the mediation effect between two or more mediator factors was not possible. These studies failed to consider other important factors from the perspective of Bangladesh, such as the intention to use a PHC system, self-efficacy, and health awareness. Another study identified the factors that influence the adoption of eHealth by a specific user group, such as patients from hospitals in the capital city of Dhaka in Ban- 
gladesh [13]. However, this study did not reflect the behavior of other user groups.

Despite the potential benefits, the adoption rate of eHealth technology by citizens in Bangladesh is still low [13]. Yet, no study focused on the use of eHealth technology by urban corporate people in Bangladesh.

Grameen Communications, Bangladesh, and Kyushu University, Japan, have jointly developed a human-assisted PHC system [14]. A PHC is an eHealth system that aims to provide affordable primary healthcare services to prevent severity or to control non-communicable diseases (NCDs). A PHC system has four modules: 1) a set of medical devices, 2) a software system to collect and archive medical records, 3) healthcare workers to make the clinical measurements and explain ePrescriptions, and 4) ICT-trained call center doctors. Consumers come to the service point, and a health checkup is conducted by pre-trained healthcare workers. If needed, the consumer is connected to the call center doctors for a consultancy. The clinical measurements addressed by a PHC are as follows: 1) blood pressure, 2) pulse rate, 3) body temperature, 4) oxygenation of blood (SpO2), 5) arrhythmia, 6) body mass index (BMI), 7) waist, hip, and $\mathrm{W} / \mathrm{H}$ ratio, 8) blood glucose, 9) blood cholesterol, 10) blood hemoglobin, 11) blood uric acid, 12) blood grouping, 13) urinary sugar, and 14) urinary protein.

Because a PHC is a new system and the doctor is virtual, patients cannot consult a remote doctor in person. To increase the acceptance and future use of a PHC system, the developers tested the system in different communities with different characteristics, such as urban corporate people. Empirically testing the suggested factors found in the previous studies in real settings is necessary because only the confirmed factors can be applied as a basic model for each technological context and user group [15]. Different factors may affect the acceptance of the same eHealth technology for different user groups [16], and the rank of the factors may differ [17]. In contrast, the established acceptance model can be extended by incorporating new variables in specific technological contexts and user groups [15]. To evaluate and increase the acceptance of a PHC system before implementing it on a large scale, understanding the factors that are more highly valued by potential user groups is necessary. Because the low usage of ICT-based systems has been identified as a major factor for the "productivity paradox," low returns from organizational investments occurred [18].

Therefore, the purpose of this study is to determine the factors that influence the adoption and future use of a PHC system. This study proposes a model by newly incorporating a "health awareness" factor that can investigate the factors behind the use of a PHC system by the urban corporate in Bangladesh. Health awareness is an important factor from the perspective of Bangladesh because the people in this country lack the high health awareness needed to prevent NCDs.

For the interviews, this study selected people from the urban area who work in institutions under the Grameen Bank complex in Dhaka, Bangladesh. Because institutional people have significant workloads and remain seated for a long time to complete their tasks, they are more likely to develop NCDs. The prevalence of 
risk factors, such as hypertension, obesity, diabetes, and low physical activity, for developing NCDs is also higher among urban than rural people in Bangladesh [19].

In addition, little chance exists to engage in physical activities among the urban people in Bangladesh because of a lack of playgrounds, parks, walkable footpaths, and safe roads for cycling [19]. Therefore, it is important to control and prevent the seriousness of NCDs by getting regular health checkups. However, most people are not interested in spending money and time on preventive healthcare services. Institutional people in Bangladesh lack health insurance and high health awareness, do not get routine mandatory health checkups, and are not habituated to use ICT-based healthcare services. Moreover, to get a checkup, they need to visit a hospital in traffic-congested areas and wait in a long, laborious queue. In this situation, the authors conducted a survey of 264 urban corporate people to understand the underlying factors that could influence them to use a PHC system in the future.

\section{Theoretical Basis for Building the Proposed Model}

Several previous studies explored the factors that influence the use behavior of new technology. The present study reviews previous studies and develops the proposed model. The theory of reasoned action (TRA) is a major theory that explains people's behavior [20]. Based on the TRA, the theory of planned behavior was developed as is an extension of the TRA [21]. The technology acceptance model (TAM) was developed using these models as a foundation [22]. TAM is a major theory used to understand how users come to accept and use new technology but does not include some important external variables. The TAM2 was developed based on the basic TAM by adding the determinants of perceived usefulness and usage intention constructs. Subsequently, the unified theory of acceptance and use of technology (UTAUT) model was developed by adding to the basic TAM facilitating conditions and social influences [23].

Based on TAM [24], TAM2 [25], UTAUT [23], and other existing technology acceptance models, the present study proposes a model that can investigate the factors affecting the use of a PHC system. Moreover, this study argues that health awareness may directly affect the use of a PHC system.

\section{Theoretical Model and Hypotheses Development}

This study develops a hypothetical model (Figure 1) that is tested for urban corporate people. A number of key factors are selected that were validated by previous studies, and hypotheses regarding the relationships of these factors are proposed based on empirical findings and theoretical reasoning.

Perceived Usefulness:

Perceived usefulness is defined as the degree to which a person believes that using a particular technology would enhance his or her job performance [24] [25]. In other words, users may feel that using a PHC system will improve their 


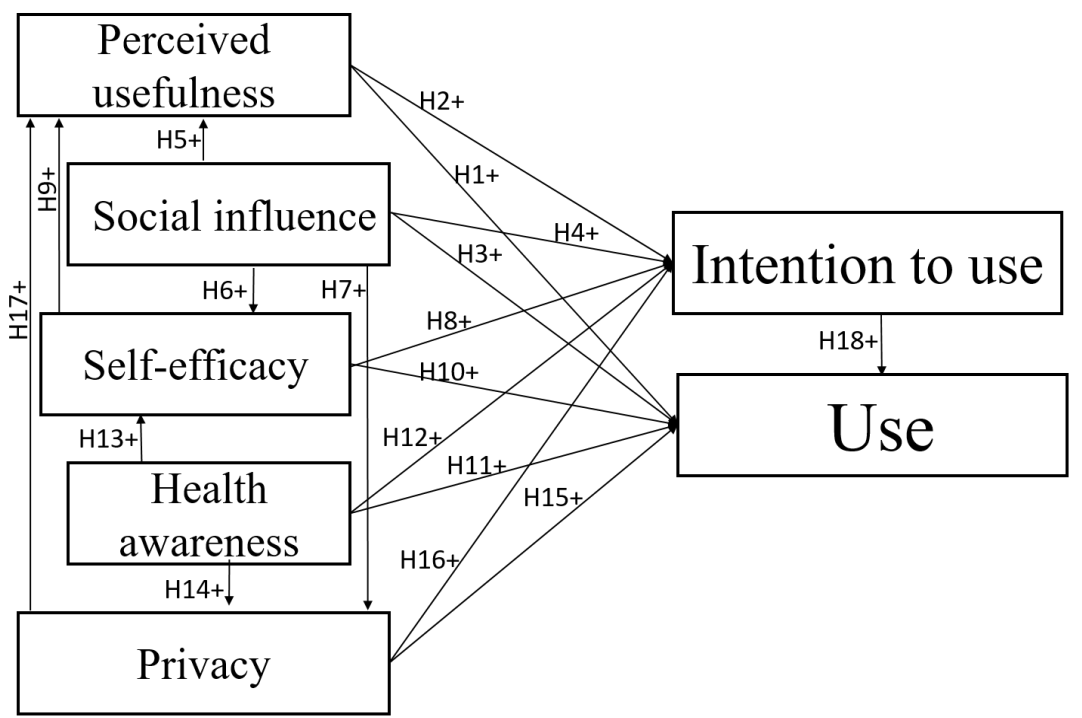

Figure 1. Hypothetical model. Note: $\mathrm{H}$ indicates a hypothesis and + indicates a positive relationship between two variables.

health status. One study revealed a significant correlation between perceived usefulness and self-predicted future use [24]. Another previous study found a positive effect of perceived usefulness on the intention to use eHealth technology [26]. In many other studies, perceived usefulness was also found to be a significant predictor of behavioral intention [6] [27] [28] [29]. Therefore, the following hypothesis is developed.

$H 1$ : Perceived usefulness has a positive and direct effect on the use of a PHC system.

$H 2$ : Perceived usefulness has a positive effect on intention to use.

\section{Social influence:}

Social influence is the extent to which consumers realized that others-who are important to them-believe that they should use a specific technology [30]. Previous studies defined social influence as encouragement from friends, coworkers, or family members to using preventive eHealth services [30] [31]. Social influence includes both social and subjective norms as well [23]. Social norms consist of two influences: 1) informational norm to enhance knowledge and 2) normative to conform to expectations of others [32]. Subjective norms concern the perceived social pressures to undertake or not undertake a behavior [33] [34]. Some studies revealed that social influence had a significant impact on intention to use [8] [23] [26]. Other studies also identified social influence as the determinant of the acceptance of eHealth [35]. Yet other studies found that social influence had a significant impact on perceived usefulness [36]. Therefore, the following hypotheses are developed.

H3: Social influence has a positive and direct effect on the use of a PHC system.

H4: Social influence has a significant influence on intention to use.

$H 5$ : Social influence has a significant influence on perceived usefulness. 
H6: Social influence has a significant impact on self-efficacy. Because friends, family members, or loved ones can be encouraged to perform any action, a person's confidence for performing an action becomes stronger.

$H 7$ : Social influence has a significant effect on privacy.

Self-Efficacy:

Perceived self-efficacy is defined as the judgment of one's ability to use technology to accomplish a particular job or task [23] [37]. In other words, self-efficacy is defined as one's confidence in one's ability to perform a behavior successfully that leads to a valued outcome [29] [31] [38]. Self-efficacy influences one's aspirations and goals [31] [38]. A person's self-efficacy beliefs affect his or her tendency to use eHealth technology [39]. A person with high self-efficacy is more likely than a person with low self-efficacy to believe that using eHealth technology will generate better health outcomes [31]. Self-efficacy has a significant influence on perceived usefulness [16] and significantly and positively influences behavioral intention [31] [40]. Therefore, the following hypotheses are developed.

H8: Self-efficacy has a positive and direct effect on the use of a PHC system.

H9: Self-efficacy has a significant influence on perceived usefulness.

$H 10$ : Self-efficacy has a positive effect on intention to use.

Health A wareness.

Health awareness is measured to assess the degree of readiness for undertaking any health actions [41] [42]. This construct reflects a person's readiness to do something for his or her health [43]. Healthy behavior was found to be a significant component of the self-efficacy of using eHealth technology [31]. When people get ready to use eHealth technology to improve their health conditions, they are more concerned about the privacy of the system [44]. Thus, a more health-conscious person will have high self-efficacy to believe that using a PHC system will improve his or her health condition. Therefore, the following hypotheses are developed.

H11: Health awareness has a positive and direct effect on the use of a PHC system.

$H 12$ : Health awareness has a significant effect on intention to use.

$H 13$ : Health awareness has a significant effect on self-efficacy.

H14: Health awareness has a significant effect on privacy.

Privacy.

The importance of the privacy concern is increasing gradually in the healthcare sector [45].

Privacy is defined as the extent to which a respondent believes that a PHC system will not compromise his or her privacy [46]. Information privacy is defined as the extent to which individuals are disturbed about the information collection practices of others and how the obtained information will be used [44] [47]. Privacy has a significant influence on behavioral intention and perceived usefulness [6]. A consumer who has a more positive perception about the privacy concern offered by a PHC system is expected to be more positive about using 
the system. Therefore, the following hypotheses are developed.

H15: Privacy has a positive and direct effect on the use of a PHC system.

H16: Privacy has a positive effect on intention to use.

H17: Privacy has a significant effect on perceived usefulness.

Intention to Use.

Behavioral intention is defined as a person's perceived likelihood that he or she will perform the specific behavior. Intention contains four different elements: the behavior, the target object at which the behavior is directed, the situation in which the behavior is to be performed, and the time at which the behavior is to be performed [20]. If one can obtain a measure of the intention immediately before the performance of the behavior, the intention will accurately predict the behavior. However, to predict future behavior, one cannot depend only on the measure of intention-other variables must also be considered [48]. Therefore, the following hypothesis is developed.

H18: Intention to use has a positive and direct effect on the use of a PHC system.

\section{Self-Predicted Future Use:}

This study uses self-predicted future use of a PHC system as a final dependent variable (use). Self-predicted behavior or behavioral expectations is defined as one's estimated likelihood of performing an action, whether or not a commitment has been made. Behavioral expectations should more accurately predict future behavior than behavioral intention alone [49].

\section{Methodology}

\subsection{Study Place}

A cross-sectional survey was conducted in August 2018 among all office workers who agreed to participate in PHC health checkups and eHealth services in the Grameen Bank Complex in Dhaka, Bangladesh. The Grameen Bank Complex holds several different offices, such as Grameen Bank, Grameen Communications, other non-government organizations, and private companies, with more than 500 workers. This study recruited participants from these 18 institutions for several reasons. People working in institutions are very busy and most of the time they work sitting in seats. Therefore, they are more likely to develop NCDs. In addition, little chance exists for physical activities among urban people in Bangladesh because of a lack of playgrounds, parks, walkable footpaths, and safe roads for cycling [19]. Institutional people in Bangladesh do not have health insurance and high health awareness, do not get routine mandatory health checkups, and are not habituated to use ICT-based healthcare services.

\subsection{Data Collection}

Prior to the implementation of PHC services, awareness events and prior notification to each office were made to provide information on the availability of PHC services. 
Those potential users are expected to understand the perceived benefits of using a PHC system. A pilot survey was conducted to test whether or not the questionnaire items were understandable to respondents. The questionnaire was finalized based on feedback from the pilot survey. Then, immediately after receiving PHC services, the survey was given to those who came to the PHC service providing point at the Grameen Bank Complex and received the service. Questions were asked by pre-trained data collectors in Bangladesh.

Data were collected from a sample of 264 people through a face-to-face structured questionnaire survey. A simple random sampling method was used to collect data from the respondents. All participants involved were treated based on the safety procedure described in the "Helsinki Declaration 2013" [50]. The data were secured at the data center, and participants' privacy is protected. Only researchers, data entry officers, and data managers could access the data with a security password.

\subsection{Measures}

All of the questionnaire items for latent constructs were taken from prior studies and modified according to the context of a PHC and Bangladesh (see Appendix A).

\subsection{Questionnaire Design}

The questionnaire consists of two parts: 1) Part A (socio-demographic information): age, gender, education, and experience and 2) Part B (cognitive or perceptional questions): psychological factors. The respondents read each statement and rated them on a five-point Likert scale by placing $\sqrt{ }$ (tick) in the number that best describes them, where $1=$ strongly disagree, $2=$ disagree, $3=$ neither disagree nor agree, $4=$ agree, and $5=$ strongly agree.

\subsection{Ethical Approval}

The authors obtained ethical approval from the National Research Ethics Committee (NREC) of the Bangladesh Medical Research Council with approval no. 18325022019.

\subsection{Data Analysis Method}

Two statistical methods were applied to analyze the data: exploratory factor analysis and structural equation modeling.

Exploratory factor analysis (by using SPSS 25.0) is used to measure latent factors in our proposed research model, and structural equation modeling (by using the AMOS SPSS 25.0 tool) is used to identify cause and effect relationships among the factors. Before the estimation of the hypothetical model, exploratory factor analysis (using the maximum likelihood extraction method and the Promax rotation method) was conducted to measure factors with the Cronbach's alpha reliability coefficient. 


\section{Results}

A descriptive summary of respondents' socio-demographic characteristics is provided in Table 1.

The results of explanatory factor analysis with reliability coefficients are shown in Appendix A. The reliability coefficient was assessed to ensure that all questionnaire items measured the same underlying factors. Items with loadings lower than 0.4 were dropped, and then the factor analysis was recalculated. All remaining items were highly loaded on each of the corresponding factors. Specifically, the reliability coefficient (Cronbach's alpha) for perceived usefulness was 0.902 , health awareness 0.781 , social influence 0.882 , privacy 0.904 , use 0.741 , intention to use 0.898 , and self-efficacy 0.855. All of the Cronbach's alpha values are greater than the threshold of 0.70 , indicating that all questionnaire items reliably measure each factor [51].

Table 2 provides the common goodness of model fit indices, the recommended value, and the results of the model.

By comparing all indices with their corresponding recommended values as suggested by previous studies [52] [53] and shown in Table 2, the model indicates a better fit to the data (Figure 2).

Table 1. Summary of respondents' socio-demographic characteristics $(n=264)$.

\begin{tabular}{|c|c|c|c|c|}
\hline $\begin{array}{l}\text { Variable } \\
\text { Name }\end{array}$ & Definition & Description & Mean & $\begin{array}{l}\text { Standard } \\
\text { Deviation }\end{array}$ \\
\hline Age & Age of the respondent & 34 - 74 years, continuous data & 49.50 & 7.43 \\
\hline Gender & $\begin{array}{c}\text { Gender of } \\
\text { the respondent }\end{array}$ & Male $=1 ;$ female $=0$ & 0.84 & 0.37 \\
\hline Education & $\begin{array}{l}\text { Education completed } \\
\text { by the respondent }\end{array}$ & $\begin{array}{l}1=\text { No education (no school entered); } 2= \\
\text { Primary school completed; } 3=\text { Secondary } \\
\text { school completed; } 4=\text { High school completed; } \\
\quad 5=\text { Vocation school completed; } \\
6 \text { = College/University completed; } 7=\text { Higher } \\
\text { (Master or Doctor) completed; } 8=\text { Others }\end{array}$ & 5.66 & 1.89 \\
\hline Experience & $\begin{array}{c}\text { Experience using any } \\
\text { eHealth service }\end{array}$ & $\mathrm{Yes}=1 ; \mathrm{No}=0$ & 0.25 & 0.44 \\
\hline
\end{tabular}

Table 2. Goodness of fit indices for structural model.

\begin{tabular}{lccc}
\hline \multicolumn{1}{c}{ Indices } & Recommended Values & Results of Model & Model Fit \\
\hline 1. Chi-square/DF & 1 to 5 & 2.587 & $<5$ good fit \\
2. RMSEA & $<0.08$ & 0.078 & $<0.08$ good fit \\
3. CFI & $>0.9$ & 0.962 & $>0.9$ good fit \\
4. GFI & $>0.9$ & 0.946 & $>0.9$ good fit \\
5. AGFI & $>0.80$ & 0.902 & $>0.8$ good fit \\
6. NFI & $>0.9$ & 0.940 & $>0.8$ good fit \\
7. $R^{2}$ & - & 0.715 & \\
\hline
\end{tabular}




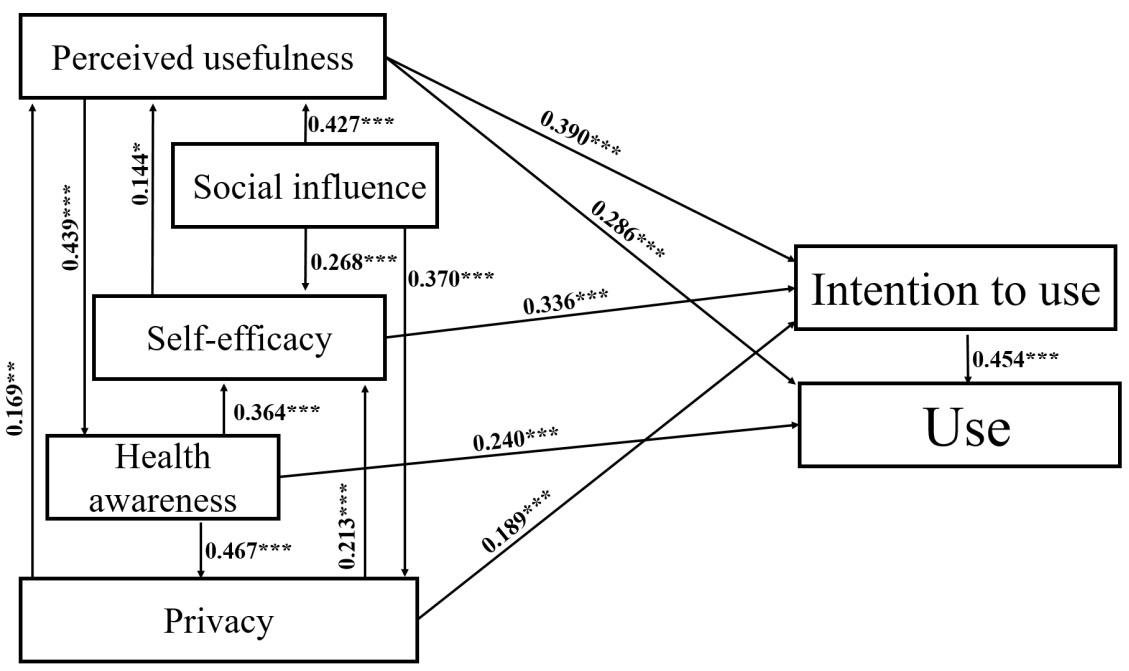

Figure 2. Estimated model. Note: ${ }^{\star},{ }^{\star *}$, and ${ }^{\star * \star}$ indicates a p-value less than $0.1,0.05$, and 0.001 , respectively. The number (path coefficients) indicates the degree of the relationship, $\mathrm{n}=264$.

The model developed in this study was able to explain $72 \%$ of the variance in the use and $61 \%$ of the variance in the intention to use. Table 3 shows the result of the hypothesis tests and the direct and indirect effect of predictors on use behavior.

The estimation of the standardized direct and indirect effects of each predictor on use permits the relative contribution of each predictor on use. If the absolute standardized total effect is taken into account, perceived usefulness is the most important predictor of use followed by intention to use and health awareness, respectively.

\section{Discussion}

This study applied a modified eHealth acceptance model by incorporating a health awareness factor into the model to understand the acceptance behavior of corporate people in Bangladesh regarding eHealth. This study provides empirical evidence for the proposed hypotheses.

This study found that perceived usefulness, intention to use, and health awareness have direct and positive effects on use behavior. Many empirical studies found significant effects of perceived usefulness and intention to use on use behavior but did not check for corporate people in developing countries and did not include the health awareness factor, which has a strong and significant effect on both intention to use and use behavior [16] [26] [54]. The three factors previously mentioned can be presented as follows.

1) Perceived usefulness: Perceived usefulness has a direct and positive effect on both use $\left(0.286^{* * *}\right)$ and intention to use $\left(0.390^{* * *}\right)$ and, thus, was also the determinant of use and the intention to use. Therefore, hypotheses $\mathrm{H} 1$ and $\mathrm{H} 2$ were accepted. Davis et al. [24] supported the result of H1. Another study found that perceived usefulness significantly influences intention [26]. 
Table 3. Result of hypotheses tests and effect analysis on use behavior.

\begin{tabular}{|c|c|c|c|c|c|c|c|}
\hline \multirow{2}{*}{ Variables } & \multicolumn{2}{|c|}{ Direct Effect } & \multicolumn{3}{|c|}{ Indirect Effect } & \multirow{2}{*}{ Total Effect } & \multirow{2}{*}{ Rank } \\
\hline & s. e & Hypothesis & s. e & Mediator & Hypothesis & & \\
\hline Perceived usefulness & 0.286 & H1 A & 0.373 & $\begin{array}{c}\text { Intention } \\
\text { Health awareness }\end{array}$ & $\mathrm{H} 2 \mathrm{~A}$ & 0.659 & 1 \\
\hline Intention to use (intention) & 0.454 & $\mathrm{H} 27 \mathrm{~A}$ & 0.000 & & & 0.454 & 2 \\
\hline Health awareness & 0.240 & $\mathrm{H} 11 \mathrm{~A}$ & 0.207 & $\begin{array}{l}\text { Privacy } \\
\text { Self-efficacy } \\
\text { Intention }\end{array}$ & $\begin{array}{l}\text { H14 A } \\
\text { H13 A } \\
\text { H12 R }\end{array}$ & 0.447 & 3 \\
\hline Social influence & 0.000 & H3 R & 0.440 & $\begin{array}{c}\text { Privacy } \\
\text { Perceived usefulness } \\
\text { Self-efficacy } \\
\text { Intention }\end{array}$ & $\begin{array}{l}\text { H7 R } \\
\text { H5 A } \\
\text { H6 A } \\
\text { H4 R }\end{array}$ & 0.440 & 4 \\
\hline Privacy & 0.000 & H15 R & 0.250 & $\begin{array}{c}\text { Intention } \\
\text { Perceived usefulness }\end{array}$ & $\begin{array}{l}\text { H16 A } \\
\text { H17 A }\end{array}$ & 0.250 & 5 \\
\hline Self-efficacy & 0.000 & H8 R & 0.247 & $\begin{array}{c}\text { Intention } \\
\text { Perceived usefulness }\end{array}$ & $\begin{array}{c}\mathrm{H} 10 \mathrm{~A} \\
\mathrm{H} 9 \mathrm{~A}\end{array}$ & 0.247 & 6 \\
\hline
\end{tabular}

Note: s.e: Standardized effect, Total effect = Direct effect + Indirect effect, A: Accepted hypothesis, R: Rejected hypothesis, -: insignificant effect (p > 0.1), Indirect effect is the product of two effects. The final endogenous construct is the self-predicted future use; $\mathrm{n}=264$.

2) Intention to use: Intention to use has a positive and direct effect on use $\left(0.454^{* *}\right)$. Therefore, hypothesis $\mathrm{H} 17$ was accepted. Some previous studies supported this finding [8] [26].

3) Health awareness: Health awareness has a positive and direct effect on use $\left(0.240^{\star * *}\right)$. Respondents who are more health-conscious believe that using a PHC system will help keep them healthier. Therefore, hypothesis H11 was accepted. A former study has shown "self-perception about health" as a significantly influencing factor of behavioral intension to use a technology such as Electronic Health Record (EHR) portal [55], whereas, the "subjective health belief" is described as the same for taking decision to consult with a general practitioner by other researchers [56]. Comparing with these two factors described in Ref. [55] [56]. "Health awareness" has certainly been identified as an influencing factor for the corporates' future use of eHealth technology.

The modification indices showed two additional path coefficients from perceived usefulness to health awareness; that is, a person decides to take any health-related action based on the perceived benefits of taking the action [57].

Moreover, from privacy to self-efficacy, that is, a person who has a more positive perception about the privacy concern offered by a PHC system will be more self-confident when using the system. Age, gender, education, experience using any eHealth service, privacy, social influence, and self-efficacy do not have a significant direct effect on use. However, privacy and self-efficacy have a significant and positive effect on the intention to use. Age, gender, and education do not influence the intention to use. This result is consistent with a previous study [58].

Therefore, perceived usefulness, intention to use, and health awareness are the factors that strongly determine the future use of a PHC system. 


\section{Limitations and Future Directions}

This study is limited by geographical scaling: the survey was conducted in one country and focused on only 12 institutions. Thus, the results may raise a concern over the generalizability of the findings, and scope exists to make the findings more generalized by examining additional countries and institutions.

Given the cross-sectional design, the present study cannot determine the actual use. Hence, a future study should consider a longitudinal approach through which participants are interviewed severally over a period. In addition, a few variables could be added, such as trust in a PHC system and facilitating conditions, to understand additional insights into the use of eHealth technology by urban corporate people.

\section{Contributions}

\subsection{Theoretical}

The theoretical model developed in this study could support attempts to extend eHealth technology acceptance theories by incorporating the health awareness factor. This study identified health awareness as having a significant influence on the corporate's future use of eHealth for regular health checkups in a developing country. This study checked the complete model and identified the mediation effect between two or more mediator factors.

\subsection{Practical}

The findings of this study offer proactively important practical guidelines to service providers, implementers, and policymakers to successfully plan their implementations and make them sustainable, make better use of their resources, and promote the use of eHealth technology such as a PHC system. The results of this study can also contribute to policymaking to reduce the morbidity rate in the country.

\section{Conclusions}

Despite the inherent limitations of an exploratory study, this research has the merit of identifying, for the first time, the key psychological factors behind the use of eHealth technology by urban corporate people.

Based on the total effect (shown in Table 3), increasing the perception of usefulness (perceived usefulness) of the system followed by intention to use and health awareness, which were also found to have a direct and positive effect on use behavior, appears necessary to enhance the use of a PHC system. The social influence did not appear to be a determinant of use because corporate people are literate and earn money. Therefore, they make decisions based on their judgment and do not care about others' opinions. However, the previous study found a social reference to be the most significant predictor of the acceptance of a PHC system by the rural people in Bangladesh [2]. Social influence has an insignificant effect on intention to use, which is consistent with a past study [32]. Gend- 
er, education, and age do not influence intention to use and use.

Service providers, policymakers, and implementers should attempt to enhance the positive factors among consumers and, in particular, should focus on the benefits of using a PHC system. When individuals perceive the benefits of using a PHC system, they want to use it.

For policy recommendations, perceived usefulness is determined as the most important predictor of use behavior. In other words, providing an opportunity to use a PHC system, for example, could promote the perception of its usefulness. Health awareness should also be a focus. Therefore, enhancing health awareness among people through social media, television, word of mouth, and different programs is necessary to promote the use of eHealth technology for regular health checkups.

\section{Acknowledgements}

This research has been supported by multiple organizations. JSPS KAKENHI, Grant Number 18K11529, and the Future Earth Research Fund, Grant Number 18-161009264 jointly financed the core research. The Institute of Decision Science for a Sustainable Society (IDS3), Kyushu University, Japan, provided travel expenses for data collection, and Grameen Communications, Bangladesh, provided technical assistance.

\section{Conflicts of Interest}

The authors declare that there is no conflict of interest.

\section{References}

[1] Tsiknakis, M. and Kouroubali, A. (2009) Organizational Factors Affecting Successful Adoption of Innovative eHealth Services: A Case Study Employing the FITT Framework. International Journal of Medical Informatics, 78, 39-52. https://doi.org/10.1016/j.ijmedinf.2008.07.001

[2] Hossain, N., Yokota, F., Sultana, N. and Ahmed, A. (2018) Factors Influencing Rural End-Users' Acceptance of e-Health in Developing Countries: A Study on Portable Health Clinic in Bangladesh. Telemedicine and e-Health, 25, 221-229. https://doi.org/10.1089/tmj.2018.0039

[3] World Health Organization and International Bank for Reconstruction and Development (2017) Tracking Universal Health Coverage: 2017 Global Monitoring Report.

[4] Global Health Workforce Crisis (2013)

[5] Trading Economics. https://tradingeconomics.com/bangladesh/physicians-per-1-000-people-wb-data.ht $\underline{\mathrm{ml}}$

[6] Cocosila, M. and Archer, N. (2014) Perceptions of Chronically Ill and Healthy Consumers about Electronic Personal Health Records: A Comparative Empirical Investigation. BMJ Open, 4, e005304. https://doi.org/10.1136/bmjopen-2014-005304

[7] Feijt, M.A., De Kort, Y.A.W., Bongers, I.M.B. and IJsselsteijn, W.A. (2018) Perceived Drivers and Barriers to the Adoption of eMental Health by Psychologists: 
The Construction of the Levels of Adoption of eMental Health Model. Journal of Medical Internet Research, 20, e153. https://doi.org/10.2196/jmir.9485

[8] Tavares, J. and Oliveira, T. (2017) Electronic Health Record Portal Adoption: A Cross Country Analysis. BMC Medical Informatics and Decision Making, 17, 97. https://doi.org/10.1186/s12911-017-0482-9

[9] Luna, D., Almerares, A. and Mayan, J.C. (2019) Health Informatics in Developing Countries: Going beyond Pilot Practices to Sustainable Implementations: A Review of the Current Challenges. Healthcare Informatics Research, 20, 3-10. https://doi.org/10.4258/hir.2014.20.1.3

[10] Adenuga, K.I., Iahad, N.A. and Miskon, S. (2017) Towards Reinforcing Telemedicine Adoption amongst Clinicians in Nigeria. International Journal of Medical Informatics, 104, 84-96. https://doi.org/10.1016/j.ijmedinf.2017.05.008

[11] Zailani, S., Gilani, M.S. and Nikbin, D. (2014) Determinants of Telemedicine Acceptance in Selected Public Hospitals in Malaysia: Clinical Perspective. Journal of Medical Systems, 38, 111. https://doi.org/10.1007/s10916-014-0111-4

[12] Hossain, M.N., Okajima, H., Kitaoka, H. and Ahmed, A. (2017) Consumer Acceptance of eHealth among Rural Inhabitants in Developing Countries (A Study on Portable Health Clinic in Bangladesh). Procedia Computer Science, 111, 471-478. https://doi.org/10.1016/j.procs.2017.06.049

[13] Hoque, M.R., Bao, Y. and Sorwar, G. (2017) Investigating Factors Influencing the Adoption of e-Health in Developing Countries: A Patient's Perspective. Informatics for Health and Social Care, 42, 1-17. https://doi.org/10.3109/17538157.2015.1075541

[14] Sampa, M.B., et al. (2019) A Framework of Longitudinal Study to Understand Determinants of Actual Use of the Portable Health Clinic System. In: HCI International, 11587 LNCS, Springer Verlag, New York, 323-332. https://doi.org/10.1007/978-3-030-21935-2_24

[15] Rahimi, B., Nadri, H., Lotfnezhad Afshar, H. and Timpka, T. (2018) A Systematic Review of the Technology Acceptance Model in Health Informatics. Applied Clinical Informatics, 9, 604-634. https://doi.org/10.1055/s-0038-1668091

[16] Handayani, P.W., Hidayanto, A.N., Pinem, A.A., Hapsari, I.C., Sandhyaduhita, P.I. and Budi, I. (2017) Acceptance Model of a Hospital Information System. International Journal of Medical Informatics, 99, 11-28. https://doi.org/10.1016/j.ijmedinf.2016.12.004

[17] Hidayanto, N., Pinem, A.A., Sandhyaduhita, P.I. and Budi, I. (2018) Hospital Information System User Acceptance Factors: User Group Perspectives. Informatics for Health and Social Care, 43, 84-107. https://doi.org/10.1080/17538157.2016.1269109

[18] Sichel, D.E. (1997) The Computer Review: An Economic Perspective. Brookings Institute, Washington DC.

[19] Zaman, M.M., Rahman, M.M., Rahman, M.R., Bhuiyan, M.R., Karim, M.N. and Chowdhury, M.A.J. (2016) Prevalence of Risk Factors for Non-Communicable Diseases in Bangladesh: Results from STEPS Survey 2010. Indian Journal of Public Health, 60, 17-25. https://doi.org/10.4103/0019-557X.177290

[20] Fishbein, I. and Ajzen, M. (1975) Formation of Intentions. In: Belief, Attitude, Intention, and Behavior. An Introduction to Theory and Research, Addison-Wesley, Reading, MA, 288-334.

[21] Icek, A. (1991) The Theory of Planned Behavior. Organizational Behavior and Human Decision Processes, 50, 179-211. ttps://doi.org/10.1016/0749-5978(91)90020-T 
[22] Fred, D., Richard, P. and Paul, R. (1989) User Acceptance of Computer Technology: A Comparison of Two Theoretical Models. Management Science, 35, 982-1003. https://doi.org/10.1287/mnsc.35.8.982

[23] Venkatesh, V., Morris, M.G., Davis, G.B. and Davis, F.D. (2003) User Acceptance of Information Technology: Toward a Unified View. MIS Quarterly, 27, 425-478. https://doi.org/10.2307/30036540

[24] Davis, F.D. (1989) Perceived Usefulness, Perceived Ease of Use, and User Acceptance of Information Technology. MIS Quarterly, 13, 319-340. https://doi.org/10.2307/249008

[25] Venkatesh, V. and Davis, F.D. (2000) A Theoretical Extension of the Technology Acceptance Model: Four Longitudinal Studies. Management Science, 46, 186-205. https://doi.org/10.1287/mnsc.46.2.186.11926

[26] Hoque, R. and Sorwar, G. (2017) Understanding Factors Influencing the Adoption of mHealth by the Elderly: An Extension of the UTAUT Model. International Journal of Medical Informatics, 101, 75-84. ttps://doi.org/10.1016/j.ijmedinf.2017.02.002

[27] Deng, Z. (2013) Understanding Public Users' Adoption of Mobile Health Service. International Journal of Mobile Communications, 11, 351-373. https://doi.org/10.1504/IJMC.2013.055748

[28] Koivumäki, T., Pekkarinen, S., Lappi, M., Vaïsänen, J., Juntunen, J. and Pikkarainen, M. (2017) Consumer Adoption of Future MyData-Based Preventive eHealth Services: An Acceptance Model and Survey Study. Journal of Medical Internet Research, 19, 1-13. https://doi.org/10.2196/jmir.7821

[29] Sun, Y., Wang, N., Guo, X. and Peng, Z. (2013) Understanding the Acceptance of Mobile Health Services: A Comparison and Integration of Alternative Models. Electronic Commerce Research, 14, 183-200.

[30] Venkatesh, V., Thong, J. and Xu, X. (2012) Consumer Acceptance and Use of Information Technology: Extending the Unified Theory of Acceptance and Use of Technology. MIS Quarterly, 36, 157-178. https://doi.org/10.2307/41410412

[31] Koivumäki, T., Pekkarinen, S., Lappi, M., Vaïsänen, J., Juntunen, J. and Pikkarainen, M. (2013) Consumer Adoption of Future My Data-Based Preventive eHealth Services: An Acceptance Model and Survey Study. Journal of Medical Internet Research, 11, 1-13.

[32] Hsu, C.L. and Lin, J.C.C. (2008) Acceptance of Blog Usage: The Roles of Technology Acceptance, Social Influence and Knowledge Sharing Motivation. Information \& Management, 45, 65-74. https://doi.org/10.1016/j.im.2007.11.001

[33] Azjen, I. (1991) The Theory of Planned Behavior. Organizational Behavior and Human Decision Processes, 50, 179-211. https://doi.org/10.1016/0749-5978(91)90020-T

[34] O’Neal, P.W. (2007) Motivation of Health Behavior. Nova Science Publishers, Inc., New York.

[35] Hennemann, S., Beutel, M.E. and Zwerenz, R. (2017) Ready for eHealth? Health Professionals' Acceptance and Adoption of eHealth Interventions in Inpatient Routine Care. Journal of Health Communication, 22, 274-284. https://doi.org/10.1080/10810730.2017.1284286

[36] Wirtz, B.W., Mory, L. and Ullrich, S. (2012) eHealth in the Public Sector: An Empirical Analysis of the Acceptance of Germany's Electronic Health Card. Public Administration, 90, 642-663. https://doi.org/10.1111/j.1467-9299.2011.02004.x

[37] Rockmann, R. and Gewald, H. (2015) Elderly People in eHealth: Who Are They? 
Procedia Computer Science, 63, 505-510.

https://doi.org/10.1016/j.procs.2015.08.376

[38] Bandura, A. (2004) Health Promotion by Social Cognitive Means. Health Education \& Behavior, 31, 143-164. https://doi.org/10.1177/1090198104263660

[39] Kelley, H., Chiasson, M. and Downey, A. (2011) The Clinical Impact of eHealth on the Self-Management of Diabetes: A Double Adoption Perspective. Journal of the Association for Information Systems, 12, 208-234. https://doi.org/10.17705/1jais.00263

[40] De Veer, A.J.E., Peeters, J.M. and Anneke, L. (2015) Determinants of the Intention to Use e-Health by Community Dwelling Older People. BMC Health Services Research, 15, 103. https://doi.org/10.1186/s12913-015-0765-8

[41] Becker, M.H., Maiman, L.A., Kirscht, J.P., Haefner, D.P. and Drachman, R.H. (1977) The Health Belief Model and Prediction of Dietary Compliance: A Field Experiment. Journal of Health and Social Behavior, 18, 348-366. https://doi.org/10.2307/2955344

[42] Oude Ophuis, P.A.M. (1989) Measuring Health Orientation and Health Consciousness as Determinants of Food Choice Behavior: Development and Implementation of Various Attitudinal Scales. In: Marketing Thought and Practice in the 1990's, EMAC XVIII, 1723-1725.

[43] Schifferstein, H.N.J. and Ophuist, P.A.M.O. (1998) Health-Related Determinants of Organic Food Consumptions in the Netherlands. Food Quality and Preference, 9, 119-133. https://doi.org/10.1016/S0950-3293(97)00044-X

[44] Angst, C.M. and Agarwal, R. (2009) Adoption of Electronic Health Records in the Presence of Privacy Concerns: The Elaboration Likelihood Model and Individual Persuasion. MIS Quarterly, 33, 339-370. https://doi.org/10.2307/20650295

[45] Appari, A., Johnson, M.E. and Appari, A. (2010) Information Security and Privacy in Healthcare: Current State of Research. International Journal of Internet and Enterprise Management, 6, No. 4. https://doi.org/10.1504/IJIEM.2010.035624

[46] Vijayasarathy, L.R. (2004) Predicting Consumer Intentions to Use on-Line Shopping: The Case for an Augmented Technology Acceptance Model. Information \& Management, 41, 747-762. https://doi.org/10.1016/j.im.2003.08.011

[47] Stewart, K.A. and Segars, A.H. (2002) An Empirical Examination of the Concern for Information Privacy Instrument. Information Systems Research, 13, 36-49. https://doi.org/10.1287/isre.13.1.36.97

[48] Fishbein, I. and Ajzen, M. (1975) Prediction of Behavior. In: Belief, Attitude, Intention, and Behavior. An Introduction to Theory and Research, Addison-Wesley, Reading, MA, 335-383.

[49] Davis, F.D. and Warshaw, P.R. (1985) Disentangling Behavioral Intention and Behavioral Expectation. Journal of Experimental Social Psychology, 21, 213-228. https://doi.org/10.1016/0022-1031(85)90017-4

[50] World Medical Association Declaration of Helsinki (2013) Ethical Principles for Medical Research Involving Human Subjects.

[51] Chan, L.B. (2013) A Moral Basis for Recycling: Extending the Theory of Planned Behaviour. Journal of Environmental Psychology, 36, 96-102. https://doi.org/10.1016/j.jenvp.2013.07.010

[52] Hair, W., Anderson, J.F., Tatham, R.E. and Black, R.L. (1998) Multivariate Data Analysis. 5th Edition, Prentice-Hall, Englewood Cliffs, NJ.

[53] Liao, C.H. and Hsieh, I. (2013) Determinants of Consumer's Willingness to Pur- 
chase Gray-Market Smartphones. Journal of Business Ethics, 114, 409-424. https://doi.org/10.1007/s10551-012-1358-7

[54] Zayyad, M.A. and Toycan, M. (2018) Factors Affecting Sustainable Adoption of e-Health Technology in Developing Countries: An Exploratory Survey of Nigerian Hospitals from the Perspective of Healthcare Professionals. PeerJ, 6, e4436. https://doi.org/10.7717/peerj.4436

[55] Tavares, J. and Oliveira, T. (2016) Electronic Health Record Patient Portal Adoption by Health Care Consumers: An Acceptance Model and Survey. Journal of Medical Internet Research, 18, 1-28. https://doi.org/10.2196/jmir.5069

[56] Van De Kar, A., Knottnerus, A., Meertens, R., Dubois, V. and Kok, G. (1992) Why Do Patients Consult the General Practitioner? Determinants of Their Decision. British Journal of General Practice, 42, 313-316.

[57] Becker, M.H. (1974) The Health Belief Model and Personal Health Behavior. Health Education \& Behavior, 2, No. 4. https://doi.org/10.1177/109019817400200407

[58] Lee, E. and Han, S. (2015) Determinants of Adoption of Mobile Health Services. Online Information Review, 39, 556-573.

https://doi.org/10.1108/OIR-01-2015-0007

[59] Kuo, Y.F. and Yen, S.N. (2009) Towards an Understanding of the Behavioral Intention to Use 3G Mobile Value-Added Services. Computers in Human Behavior, 25, 103-110. https://doi.org/10.1016/j.chb.2008.07.007

[60] Reychav, I., Najami, I., Raban, D.R., McHaney, R. and Azuri, J. (2018) The Impact of Media Type on Shared Decision Processes in Third-Age Populations. International Journal of Medical Informatics, 112, 45-58. https://doi.org/10.1016/j.ijmedinf.2018.01.004

[61] De Veer, A.J.E., Peeters, J.M., Brabers, A.E.M., Schellevis, F.G. and Rademakers, J.M. (2015) Determinants of the Intention to Use e-Health by Community Dwelling Older People. BMC Health Services Research, 15, 103.

https://doi.org/10.1186/s12913-015-0765-8 


\section{Appendix A. Explanatory Factor Analysis}

\begin{tabular}{|c|c|c|c|c|c|c|c|c|}
\hline Questionnaire Items & $\begin{array}{l}\text { Perceived } \\
\text { Usefulness }\end{array}$ & $\begin{array}{c}\text { Health } \\
\text { Awareness }\end{array}$ & $\begin{array}{c}\text { Social } \\
\text { Influence }\end{array}$ & Privacy & Use & $\begin{array}{l}\text { Intention } \\
\text { to Use }\end{array}$ & Self-Efficacy & $\begin{array}{l}\text { Cronbach's } \\
\text { Alpha }\end{array}$ \\
\hline $\begin{array}{l}\text { Using a PHC system would help me better } \\
\text { manage/maintain my health [24] [25] [26] }\end{array}$ & 0.809 & -0.016 & -0.032 & 0.040 & 0.081 & -0.136 & 0.008 & \multirow{4}{*}{0.902} \\
\hline $\begin{array}{l}\text { I feel that using a PHC system would } \\
\text { increase my productivity [16] [24] [25] [26] }\end{array}$ & 0.825 & 0.052 & -0.009 & -0.001 & 0.052 & -0.046 & 0.000 & \\
\hline $\begin{array}{l}\text { I feel that a PHC system is useful in my } \\
\text { daily life [24] [25] [26] }\end{array}$ & 0.895 & 0.130 & -0.081 & -0.002 & -0.070 & 0.045 & -0.055 & \\
\hline $\begin{array}{l}\text { Using a PHC system will enhance my } \\
\text { effectiveness in my life and job [16] [24] } \\
{[25][26][59]}\end{array}$ & 0.851 & -0.123 & 0.166 & -0.058 & -0.036 & -0.033 & 0.056 & \\
\hline $\begin{array}{l}\text { People who are important to me suggest } \\
\text { using a PHC system (other than family } \\
\text { members) [16] [25] [60] }\end{array}$ & 0.028 & -0.030 & 0.646 & 0.028 & 0.102 & 0.078 & 0.051 & \multirow{3}{*}{0.882} \\
\hline $\begin{array}{l}\text { My family members prefer to use a PHC } \\
\text { system [25] [61] }\end{array}$ & 0.032 & -0.011 & 0.820 & -0.056 & 0.040 & 0.133 & -0.059 & \\
\hline $\begin{array}{l}\text { I use a PHC because my colleagues also use } \\
\text { it [16] }\end{array}$ & -0.006 & 0.049 & 0.939 & 0.044 & -0.061 & -0.087 & -0.004 & \\
\hline $\begin{array}{l}\text { I believe that the privacy of } \mathrm{PHC} \\
\text { participants is protected [26] }\end{array}$ & -0.009 & 0.107 & -0.002 & 0.842 & 0.075 & -0.032 & -0.127 & \multirow{3}{*}{0.904} \\
\hline $\begin{array}{l}\text { I believe that the personal information } \\
\text { stored in a PHC system is safe [26] }\end{array}$ & -0.037 & -0.156 & -0.008 & 0.943 & -0.003 & 0.078 & 0.074 & \\
\hline $\begin{array}{l}\text { I believe that a PHC system keeps } \\
\text { participant information secure [26] }\end{array}$ & 0.038 & 0.126 & 0.036 & 0.820 & -0.109 & -0.037 & 0.018 & \\
\hline I consider myself very health conscious [43] & 0.050 & 0.355 & 0.247 & 0.119 & -0.009 & -0.179 & 0.018 & \multirow{5}{*}{0.781} \\
\hline $\begin{array}{l}\text { I think that I take into account health a lot } \\
\text { in my life [43] }\end{array}$ & 0.043 & 0.823 & 0.016 & 0.058 & -0.065 & -0.078 & 0.006 & \\
\hline I want to improve my health condition [41] & 0.001 & 0.761 & -0.073 & -0.064 & 0.128 & 0.180 & -0.168 & \\
\hline $\begin{array}{l}\text { I want to do something good for my health } \\
\text { [41] [43] }\end{array}$ & -0.151 & 0.497 & 0.100 & -0.088 & 0.195 & 0.023 & 0.192 & \\
\hline $\begin{array}{l}\text { I think that by using a PHC system I can } \\
\text { prevent the seriousness of diseases (silent } \\
\text { killers, e.g., diabetes, stroke, heart-failure) } \\
\text { [41] }\end{array}$ & 0.063 & 0.515 & -0.055 & 0.055 & -0.057 & 0.102 & 0.196 & \\
\hline $\begin{array}{l}\text { I could get health checkups by using a PHC } \\
\text { system [23] }\end{array}$ & -0.047 & 0.005 & 0.014 & -0.020 & -0.053 & 0.090 & 0.999 & \multirow{2}{*}{0.855} \\
\hline $\begin{array}{l}\text { I feel confident that I will comply with a } \\
\text { PHC prescription [31] [60] }\end{array}$ & 0.149 & 0.085 & -0.056 & 0.007 & 0.138 & -0.108 & 0.633 & \\
\hline $\begin{array}{l}\text { I intend to use a PHC system in the future } \\
\text { [25] [26] }\end{array}$ & 0.009 & 0.008 & 0.016 & -0.003 & -0.068 & 0.883 & 0.088 & \multirow{3}{*}{0.898} \\
\hline $\begin{array}{l}\text { If a PHC system is available, I will always } \\
\text { use it [17] [25] [26] }\end{array}$ & 0.055 & 0.035 & 0.023 & -0.015 & -0.100 & 0.977 & -0.054 & \\
\hline $\begin{array}{l}\text { It would be worth it to receive a PHC health } \\
\text { service [20] }\end{array}$ & 0.009 & 0.001 & 0.019 & 0.113 & 0.279 & 0.468 & 0.021 & \\
\hline $\begin{array}{l}\text { A PHC system is a pleasant experience [13] } \\
{[26]}\end{array}$ & 0.103 & 0.000 & 0.065 & -0.105 & 0.801 & -0.066 & -0.075 & 0.741 \\
\hline
\end{tabular}




\section{Continued}

I spend time to know about a PHC system

[13] [26]

$\begin{array}{lcccccc}-0.179 & 0.074 & -0.004 & -0.018 & 0.574 & -0.115 & 0.034 \\ -0.031 & 0.015 & 0.025 & 0.088 & \mathbf{0 . 7 3 3} & 0.077 & -0.010 \\ 0.224 & -0.073 & -0.098 & 0.079 & \mathbf{0 . 6 7 4} & 0.045 & 0.075\end{array}$

I realize that using a PHC system creates many advantages [36] [49]

Note: All of the questionnaire items for latent constructs were taken from prior studies and modified according to the context of a PHC and Bangladesh. 